\title{
Sero-molecular Prevalence of Zika Virus among Pregnant Women Attending Some Public Hospitals in Lagos State, Nigeria
}

\author{
Joseph Ojonugwa Shaibu, Azuka Patrick Okwuraiwe, AbdulRokeeb Jakkari, Abuh Dennis, \\ Kabiru O. Akinyemi, Jiandong Li, Rosemary Ajuma Audu and Akeeb O. Bola Oyefolu
}

\section{ABSTRACT}

Zika virus (ZIKV) is one of the arboviruses implicated in febrile illness, microcephaly and other neurological disorders in babies whose mothers were infected during pregnancy. Information on ZIKV in Nigeria is limited. Hence, this study was aimed at investigating the seroprevalence of Zika virus among pregnant women in Lagos State.

In a cross-sectional study, blood samples collected from 352 randomly selected pregnant women in four hospitals in Lagos State were separated and plasma analyzed using Zika virus IgG and IgM capture Enzymelinked immunosorbent assay (Demeditec Diagnostics, Germany). The optical densities were read using Precision Microplate reader (Molecular devices) and cut-off calculated according to manufacturer's guide. Parameters and symptoms such as history of fever, rashes on the body, exposure to mosquito were extracted from the questionnaire and analyzed. IgM seropositive samples were screened for ZIKV RNA on RTqPCR.

Out of 352 samples screened, $7(2.0 \%)$ and $5(1.4 \%)$ of the pregnant women tested positive for IgG and IgM respectively. None tested positive for both IgG and IgM markers. Statistical analysis showed that there is no significant relationship between the symptoms analyzed in this study at 95\% Confidence interval except conjunctivitis. None of the ZIKV IgM seropositive samples tested positive for ZIKV RNA on RT-qPCR.

The results show that there is evidence of exposure to Zika virus among the population studied in Lagos, Nigeria. Also, the low level seroprevalence of the virus in the population studied indicates that there is lack of herd immunity of Zika virus infection in Lagos, Nigeria.

Keywords: ELISA, Zika, IgG, IgM, prevalence, plasma, pregnant.
Submitted: September 20, 2021

Published: October 30, 2021

ISSN: $2593-8339$

DOI: 10.24018 /ejmed.2021.3.5.1075

\section{J. O. Shaibu*}

Centre for Human Virology and Genomics, Department of Microbiology, Nigerian Institute of Medical Research, Lagos State, Nigeria.

(e-mail: josephshaibu2013@gmail.com) A. P. Okwuraiwe

Centre for Human Virology and Genomics, Department of Microbiology, Nigerian Institute of Medical Research, Lagos State, Nigeria.

(e-mail: azukaokwu@yahoo.com)

A. Jakkari

Department of Microbiology, Lagos State University (LASU), Ojo, Lagos State, Nigeria.

(e-mail: abdulroqeebjakkari@yahoo.com) A. Dennis

Centre for Infectious Disease Research, Department of Microbiology, Nigerian Institute of Medical Research, Lagos State, Nigeria.

(e-mail: bishopdennis97@gmail.com) K. O. Akinyemi

Lagos State University (LASU), Ojo, Lagos State, Nigeria.

(e-mail: koakinyemi@yahoo.com)

J. Li

Viral Haemorrhagic Fever Department,

China CDC, Beijing, China.

(e-mail: ldong121@126.com)

R. A. Audu

Department of Microbiology, Nigerian Institute of Medical Research Lagos State, Nigeria.

(e-mail: rosemaryaudu@yahoo.com) A.O B Oyefolu

Department of Microbiology, Lagos State University (LASU), Ojo, Lagos State, Nigeria.

(e-mail: aobolaoyefolu@yahoo.com)

*Corresponding Author 


\section{INTRODUCTION}

Zika virus (ZIKV), a flavivirus of the flaviviridae family was first discovered about 70 years ago among sentinel monkeys in a forest in Uganda. It is an arbovirus transmitted by Aedes spp of mosquito [1]-[3]. It has also been reportedly transmitted through mother-to-child, blood transfusion and sexual contact [4]. Globally, there have been a general silence in the research into ZIKV, between 1947 when the virus was discovered through to 2016 when it caused an unprecedented outbreak in the South Americas with implicated complications such as microcephaly, birth defects and neurological disorders [5]-[6]. There is a high level of crossreaction between ZIKV and other flaviviruses especially Dengue virus; this could result in misdiagnosis of ZIKV infection using serological testing process [7].

Majority of the persons who get infected with ZIKV do not manifest the symptoms and where symptoms exist, it is usually mild and self-limiting [8]. The most active phase of the infection in the blood is between 5-12 days; within this period, the virus can be easily detected using molecular method or serology targeting IgM or the viral antigen [9].

The pathogenesis and its defense mechanism against the immune system of the body has been a complex entity, however, a lot of studies of recent have helped to give deeper understanding into the pathogenesis, the mechanism of immune response to ZIKV, identification of host factors involved in mother-to-child transmission and vaccine developments. All these are at various stages of trials. Studies of the seroprevalence of an aetiological agent(s) of an infection helps to provide information about the immune status of the people leaving within a particular geographical region. This also helps to know the variation or similarity of the pathogen in the immune system of a particular people when compared to another group of people. This knowledge helps in developing antibody therapy which in the long run could end up in vaccine development.

In Africa, not much studies have been carried out on Zika virus; however, some works have been reported in countries like Senegal, Central African Republic, Uganda, Cameroon and Nigeria with some strains sequenced and the genomes deposited in the GeneBank [10]-[12]. This shows that there is Zika virus circulating in many African countries. However, lack of research has resulted in the paucity of knowledge of seroprevalence, molecular epidemiology, and mode of virushost interaction among humans, mosquitoes and other possible vectors of the virus especially in African countries. This study is focused on investigating the seroprevalence of Zika virus among pregnant women who attend antenatal clinic in selected hospitals within Lagos State, Nigeria.

\section{MATERIALS AND Methods}

\section{A. Ethical Consideration}

Ethical approval (IRB-17-049) for this study was obtained from the Institutional Review Board of Nigerian Institute of Medical Research (NIMR). Informed consents were filled by individuals who participated in this study. Participants were asked about their stages of pregnancy, history of fever, travel history, exposure to mosquito bites and symptoms such as rashes on the body.

\section{B. Study Design}

This was a cross-sectional study. The samples were collected between May and December 2018.

\section{Sample Population and Size}

Blood samples were collected from 352 asymptomatic pregnant women who attended antenatal clinics in four general hospitals (Alimosho General Hospital, Somolu General Hospital, Gbagada General Hospital and Randle General Hospital) in Lagos State, Nigeria. The pregnant women sampled were $\geq 18$ years of age who are within their first, second or third trimester. The sample size was determined using:

$$
\text { Sample size }=\left(Z^{2}\right) \times \operatorname{SD}(1-S d) / d^{2} ;[13],
$$

where $\mathrm{Z}=$ Normal deviation of type- 1 error, $\mathrm{Sd}=$ Standard deviation, $d=$ level of precision.

\section{Data Collection}

A simple questionnaire was administered to the participants to ascertain age, stage of pregnancy, history of fever, number of sexual partners, travel history, exposure to mosquito bite, knowledge of Zika virus, genotype, and symptoms such as conjunctivitis and rashes during pregnancy.

\section{E. Sample Collection, Processing and Storage}

Ten milliliters $(10 \mathrm{ml})$ of blood samples were collected in EDTA vacutainer tubes from pregnant women who documented their consent to participate in the study. The samples were labeled, triply packed and transported within 24 hours in cold chain to Centre for Human Virology and Genomics (CHVG), Nigerian Institute for Medical Research (NIMR). The blood samples in EDTA-anticoagulated tubes were centrifuged at $4000 \mathrm{rpm}$ for 20 minutes to obtain plasma which were stored at $-80{ }^{\circ} \mathrm{C}$ until analyzed.

\section{F. Sample Analysis}

The separated plasma samples were screened for IgG and IgM markers using Demeditec Zika Virus IgM $\mu$-capture and IgG capture ELISA kits (Demeditec Diagnostics GmbH, Germany). Samples and reagents were brought to room temperature $\left(20-25^{\circ} \mathrm{C}\right)$ and mixed before starting the assay. Washing buffer and samples were diluted according to the manufacturer's instruction. Diluted samples and controls were coated into the micro well plates provided by manufacturer. After the incubation and wash steps TMB substrate was added for colour development and the optical density was obtained by reading the absorbance using a Precision Microplate ELISA reader (Molecular Devices) at $450 / 620 \mathrm{~nm}$. The unit value of each of the samples screened were calculated using the formula provided by the manufacturer to determine sero-status of the samples. Plasma samples analyzed in the study were considered serologically positive if the calculated unit value is greater than eleven units (11 U) for both IgG and IgM.

\section{G. Detection using Real time Polymerase chain reaction (PCR)}

RNA was extracted from the IgM positive samples using Qiagen RNA extraction kit (Qiagen, Germany) according to 
the manufacturer's instruction. For the viral detection, TransScript Probe One-Step qRT-PCR SuperMix (Transgen BioTech, Beijing China) was used with in-house developed and validated primers and probes: 5'TTAAGGGAAAGGAGGCTGTAC-3' \&, 5'TTCTATTCCATCTGTCCACAATG-3', 5' - HEX TGGATTGAGAGTGAGAAGAACGACACATGGAGG 3' and 5'-TTGGAAGGCTGATAACCG -3' \& 5' GATGGGTGATTTTCTTGTCC - 3,, 5, - FAM AATTCAAAGATGATGTTGGAGCTCGACC - 3' in a duplex targeting Non-structural protein 1 (NS1) and envelope gene respectively. The process contained $0.4 \mu \mathrm{l}(10 \mu \mathrm{M})$ each of primers and probe, $10 \mu \mathrm{l}$ of the Supermix, $0.4 \mu \mathrm{l}$ of enzyme mix, 5ul of RNA template and RNAse free water in a total volume of $20 \mu \mathrm{l}$. According to the manufacturers' instruction, the qPCR process was performed at $45{ }^{\circ} \mathrm{C}$ for 5 minutes, $94{ }^{\circ} \mathrm{C}$ for 30 seconds, and 45 cycles of $94{ }^{\circ} \mathrm{C}$ for 5 seconds and $60{ }^{\circ} \mathrm{C}$ for 30 seconds.

\section{H. Statistical Analysis}

The questionnaires were analyzed using SPSS software v.22. Frequencies were used to determine the distribution of respondents; Chi-square values were generated, and the Pvalues were calculated at $95 \%$ confidence interval.

\section{RESULTS}

All participants in this study were pregnant women presenting at General Hospitals within Lagos state with the following distribution: Alimosho (17.6\%), Gbagada (27.8\%), Randle (34.7\%), and Somolu (19.9). Most Participants were in the median age of 37 years $(31.7 \%)$ while age group $\geq 40$ years recorded $6.1 \%$ (Fig 1). With respect to timing of their pregnancy. $9.7 \%$ of the pregnant women were in their first trimester, $44.2 \%$ in their second trimester and $46.1 \%$ in their third trimester. Out of the 352 participants screened for IgG and IgM markers, $7(2.0 \%)$ had anti-IgG for ZIKV while $5(1.4 \%)$ had anti-IgM for the virus. None was seropositive for both IgG and IgM markers. Furthermore, from Table I, it is seen that $3.3 \%$ of the respondents had more than one sexual partner, $6.2 \%$ had travelled out of the country in the past 12 months prior to this study, $35.8 \%$ had history of fever and $27.9 \%$ were regularly exposed to mosquito bites.

The study also shows that $31.4 \%$ had heard about Zika virus prior to this study. Table III shows that $9.5 \%$ of those above 40 years are seropositive for IgG while $2.6 \%$ of those within the age range of 30-34 years are IgM seropositive. However, there is no statistical significance between age range and seropositivity for either $\operatorname{IgG}$ or $\operatorname{IgM}$ among the respondents. In table IV, significant association was observed between those that had conjunctivitis and IgM Seropositivity $(p=0.000)$. An IgG seropositivity of $3.30 \%$ was observed among those who are regularly exposed to mosquito bite while $1.5 \%$ of those who are seldom exposed are IgG seropositive (Table III). There is no statistical significance between exposure to mosquito bite and $\operatorname{IgG}$ or $\operatorname{IgM}$ Seropositivity. $3.0 \%$ and $2.0 \%$ of the valid respondents who had history of fever are seropositive for IgG and IgM respectively with no statistically significant difference observed.

\section{A. Real Time PCR}

There was no amplification detected at both channels for the assay used on the extracted RNA from the IgM positive samples. The in-house assay was validated and checked for possible amplification of other arboviruses.

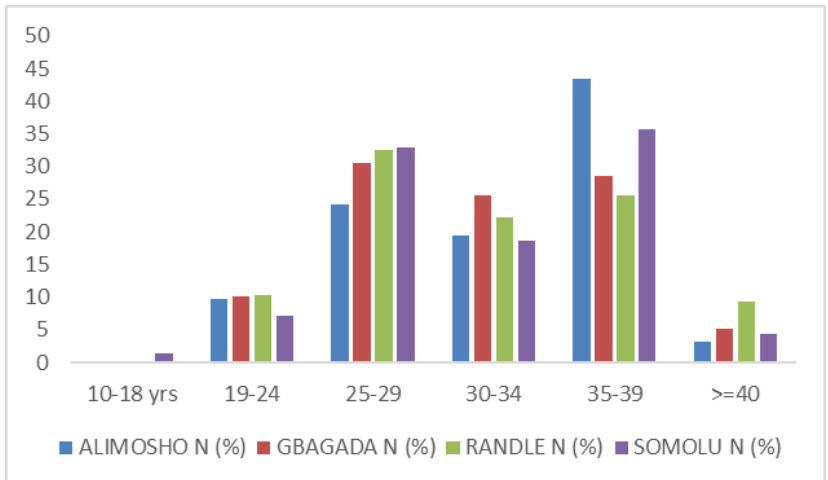

Fig. 1. Clustered bar chart showing the distribution of age range across hospitals.

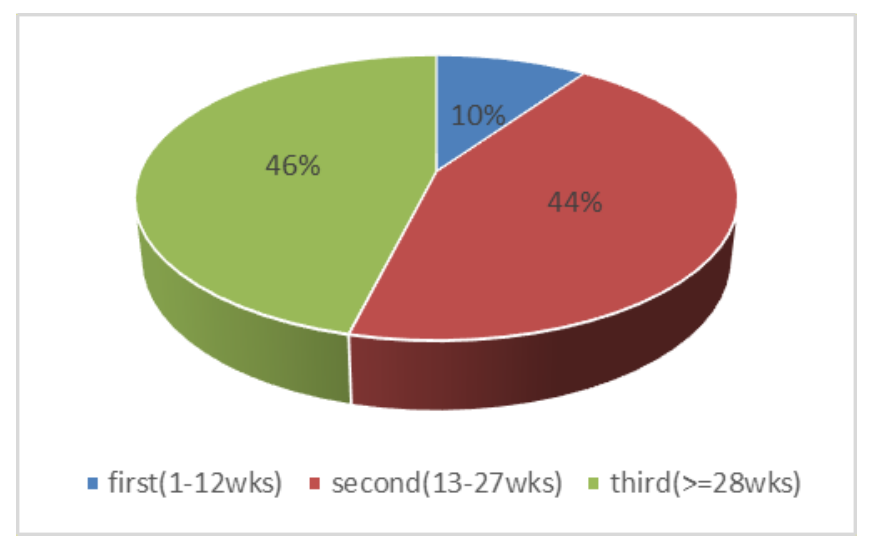

Fig. 2. Pie Chart showing the distribution of stage of pregnancy across all respondents.

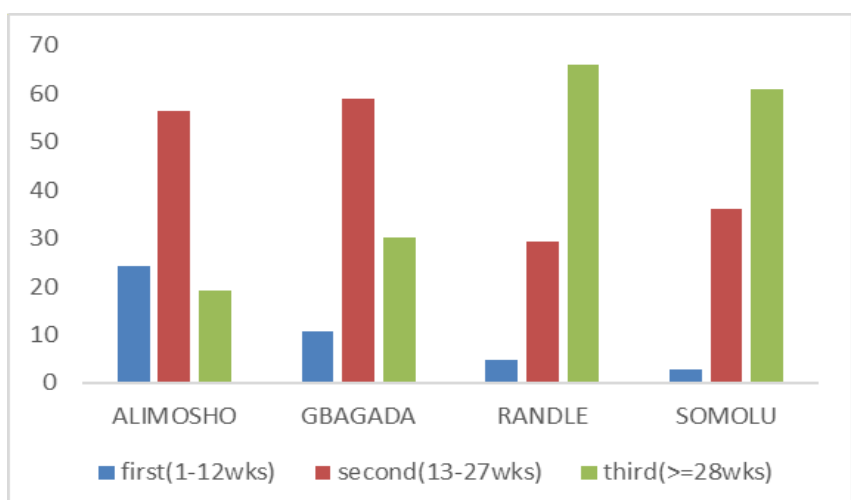

Fig. 3. Clustered bar chart showing the distribution of stage of pregnancy across hospitals. 


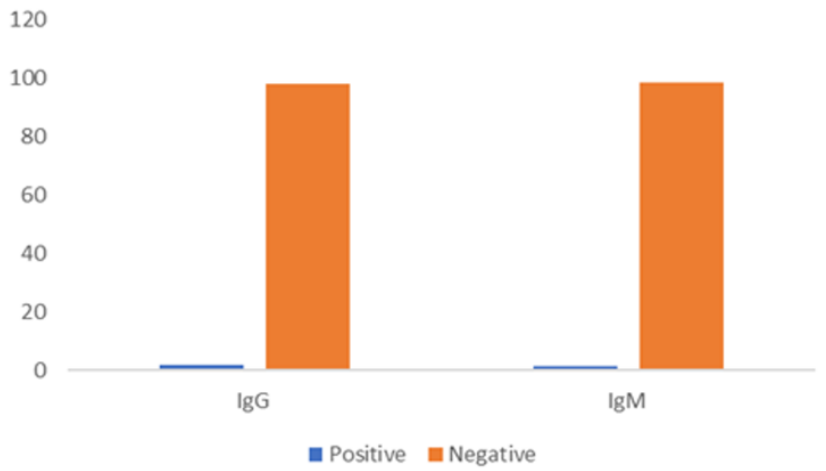

Fig. 4. Chart showing the seropositivity of respondents to IgG and IgM marker for Zika virus.

TABLE I: DISTRIBUTION OF SOME PARAMETERS ACROSS THE HOSPITALS

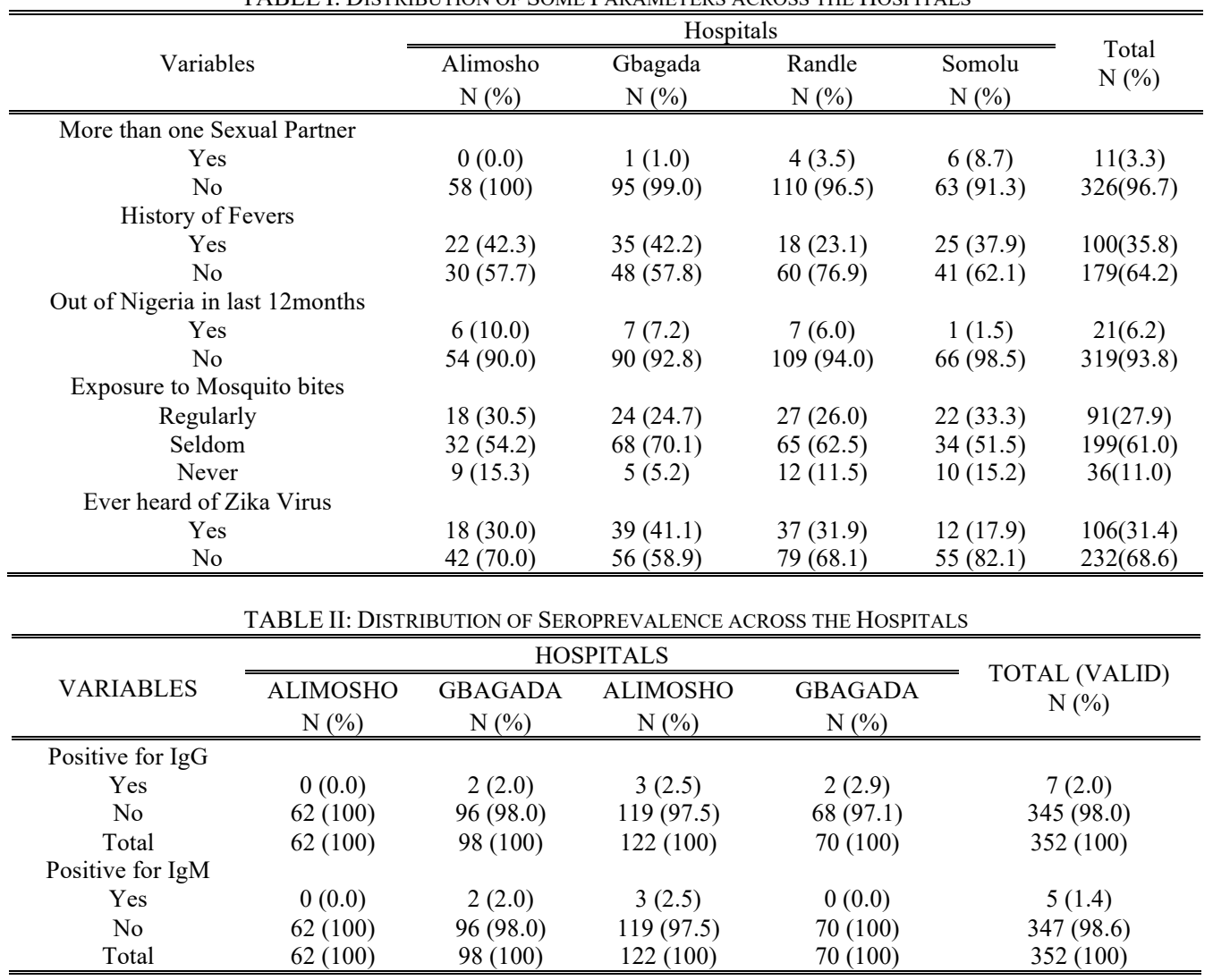

TABLE III: CHI-SQUARE ANALYSIS OF ASSOCIATED FACTORS WITH IGG AND IGM SEROPOSITIVITY

\begin{tabular}{|c|c|c|c|c|c|c|c|}
\hline \multirow[b]{2}{*}{ Variable } & \multicolumn{3}{|c|}{ IgG Positive } & \multicolumn{3}{|c|}{ IgM Positive } & \multirow{2}{*}{$\begin{array}{l}\text { Valid number } \\
\text { of respondents }\end{array}$} \\
\hline & $\mathrm{N}(\%)$ & $\chi^{2}$ value & $\begin{array}{c}\text { P value } \\
(\alpha=0.05)\end{array}$ & $\mathrm{N}(\%)$ & $\chi^{2}$ value & $\begin{array}{c}\text { P value } \\
(\alpha=0.05)\end{array}$ & \\
\hline \multicolumn{8}{|c|}{ More than one Sexual Partner } \\
\hline Yes & $0(0.00)$ & \multirow{3}{*}{0.241} & \multirow{3}{*}{0.623} & $0(0.00)$ & \multirow{4}{*}{0.137} & \multirow{4}{*}{0.712} & 11 \\
\hline No & $7(2.15)$ & & & $4(1.20)$ & & & 326 \\
\hline Total & $7(2.15)$ & & & $4(1.20)$ & & & 337 \\
\hline \multicolumn{6}{|l|}{ Hospital } & & \\
\hline Alimosho & $0(0.00)$ & \multirow{5}{*}{1.669} & \multirow{5}{*}{0.644} & $0(0.00)$ & \multirow{5}{*}{3.111} & \multirow{5}{*}{0.375} & 62 \\
\hline Gbagada & $2(2.00)$ & & & $2(2.00)$ & & & 98 \\
\hline Randle & $3(2.50)$ & & & $3(2.50)$ & & & 117 \\
\hline Somolu & $2(2.90)$ & & & $0(0.00)$ & & & 70 \\
\hline Total & $7(2.00)$ & & & $5(1.40)$ & & & 347 \\
\hline \multicolumn{8}{|l|}{ Age Range } \\
\hline $18-24$ & $1(3.00)$ & \multirow{6}{*}{8.483} & \multirow{6}{*}{0.075} & $0(0.00)$ & \multirow{6}{*}{2.198} & \multirow{6}{*}{0.699} & 33 \\
\hline $25-29$ & $0(0.00)$ & & & $1(0.90)$ & & & 106 \\
\hline $30-34$ & $2(2.60)$ & & & $1(2.60)$ & & & 76 \\
\hline $35-39$ & $2(1.80)$ & & & $2(0.90)$ & & & 110 \\
\hline$>=40$ & $2(9.50)$ & & & $0(0.00)$ & & & 21 \\
\hline Total & $7(2.00)$ & & & $4(1.20)$ & & & 347 \\
\hline \multicolumn{8}{|l|}{ Stage of Pregnancy } \\
\hline First (1-12wks) & $0(0.00)$ & \multirow{3}{*}{3.85} & \multirow{3}{*}{0.146} & $0(0.00)$ & \multirow{3}{*}{0.654} & \multirow{3}{*}{0.721} & 32 \\
\hline Second (13-27wks) & $5(3.40)$ & & & $1(0.70)$ & & & 146 \\
\hline Third $(>=28 \mathrm{wks})$ & $1(0.70)$ & & & $2(1.30)$ & & & 152 \\
\hline
\end{tabular}




\begin{tabular}{|c|c|c|c|c|c|c|c|}
\hline Total & $7(1.80)$ & & & $3(0.90)$ & & & 330 \\
\hline \multicolumn{8}{|c|}{ Out of Nigeria in last 12 months } \\
\hline Yes & $0(0.00)$ & \multirow{3}{*}{0.471} & \multirow{3}{*}{0.493} & $0(0.0)$ & \multirow[t]{3}{*}{0.266} & \multirow[t]{3}{*}{0.606} & 21 \\
\hline No & $7(2.20)$ & & & $4(1.20)$ & & & 319 \\
\hline Total & $7(2.10)$ & & & $4(1.20)$ & & & 340 \\
\hline \multicolumn{8}{|c|}{ Exposure to Mosquito bites } \\
\hline Regularly & $3(3.30)$ & \multirow{4}{*}{1.028} & \multirow{4}{*}{0.598} & $1(1.10)$ & \multirow{4}{*}{0.589} & \multirow{4}{*}{0.745} & 91 \\
\hline Seldom & $3(1.50)$ & & & $3(1.50)$ & & & 199 \\
\hline Never & $1(2.8)$ & & & $0(0.00)$ & & & 36 \\
\hline Total & $7(2.10)$ & & & $4(100.0)$ & & & 326 \\
\hline \multicolumn{8}{|c|}{ Ever heard of Zika Virus } \\
\hline Yes & $2(1.90)$ & \multirow{3}{*}{0.026} & \multirow{3}{*}{0.872} & $1(0.90)$ & \multirow{3}{*}{0.076} & \multirow{3}{*}{0.783} & 106 \\
\hline No & $5(2.20)$ & & & $3(1.50)$ & & & 232 \\
\hline Total & $7(2.10)$ & & & $4(1.20)$ & & & 338 \\
\hline
\end{tabular}

TABLE IV: CHI-SOUARE ANALYSIS OF SYMPTOMS OF ZIKA INFECTION WITH IGG AND IGM SEROPOSITIVITY

\begin{tabular}{|c|c|c|c|c|c|c|c|}
\hline \multirow[b]{2}{*}{ Variable } & \multicolumn{3}{|c|}{ IgG Positive } & \multicolumn{3}{|c|}{ IgM Positive } & \multirow{2}{*}{$\begin{array}{c}\text { Valid } \\
\text { number of } \\
\text { respondent }\end{array}$} \\
\hline & $\mathrm{N}(\%)$ & $\chi^{2}$ value & $\begin{array}{c}\text { P value } \\
(\alpha=0.05)\end{array}$ & $\mathrm{N}(\%)$ & $\chi^{2}$ value & $\begin{array}{c}\text { P value } \\
(\alpha=0.05)\end{array}$ & \\
\hline \multicolumn{8}{|c|}{ "Rashes during Pregnancy } \\
\hline Yes & $1(3.70)$ & & 0.558 & $0(0.00)$ & & 0.546 & 27 \\
\hline No & $6(2.00)$ & 0.343 & 0.558 & $4(1.20)$ & 0.364 & 0.546 & 300 \\
\hline Total & $7(100)$ & & & $4(1.20)$ & & & 327 \\
\hline \multicolumn{8}{|c|}{ Conjunctivitis in the past 12 months } \\
\hline Yes & $1(5.30)$ & 0985 & 0321 & $2(10.50)$ & & 0 & 19 \\
\hline No & $6(1.90)$ & 0.985 & 0.321 & $2(0.60)$ & $14.81 /$ & 0 & 315 \\
\hline Total & $7(2.10)$ & & & $4(1.20)$ & & & 334 \\
\hline \multicolumn{8}{|c|}{ History of Fevers } \\
\hline Yes & $3(3.00)$ & & & $2(2.00)$ & & & 100 \\
\hline No & $2(1.10)$ & 1.292 & 0.256 & $1(0.60)$ & 1.253 & 0.263 & 179 \\
\hline Total & $5(1.80)$ & & & $3(1.10)$ & & & 279 \\
\hline
\end{tabular}

\section{DISCUSSION}

In this study, we carried out a seroprevalence study of Zika virus among pregnant women in selected hospitals in Lagos state, Nigeria. The results from the study shows that there is a $2.0 \%$ and $1.4 \%$ seroprevalence of $\mathrm{IgG}$ and IgM markers for Zika virus among pregnant women in Lagos State. These low seropositivity recorded could be as a result of the time the samples were collected relative to the time of actual infection. A study reported that Anti-ZIKV IgM typically develops during the first week of infection, hence there is a high chance of not detecting $\operatorname{IgM}$ antibody in the blood after the first week of infection [14]. However, the result indicates that there is evidence of ZIKV exposure within the population studied. The low IgG seropositivity may imply that the population studied is naïve to the infection and hence may be vulnerable to future Zika viral infection outbreaks since there is no herd immunity within the population. The naivety could be as a result of less exposure to the vector of the virus as the studies was carried out in the city. This study revealed that $3.3 \%$ of the respondents who were regularly exposed to mosquito bites were IgG seropositive to Zika virus which implies that, they may have been infected by the virus at one point or the other.

Furthermore, the $1.4 \%$ seroprevalence for IgM recorded in this study shows that there is an active infection of Zika virus among the population studied. This active transmission could be said to be largely localized as record from Table III above suggested that none of the participants that were either IgG or IgM seropositive for ZIKV have travelled out of the country twelve (12) months previous to this study. Furthermore, analyzing the relationships between seropositivity and symptoms as represented on Table IV, there is a significance association between conjunctivitis and IgM seropositivity, however, when the sample was analyzed for ZIKV RNA, it was negative. This suggests that the conjunctivitis may not be as a result of ZIKV infection. The findings can be compared to the Zika sero-epidemiologic study carried out in North Central Nigeria in 2016 which found the anti-ZIKV positive rate of $4 \%$ for IgM and 3\% for IgG among pregnant women [15]. However, it is in contrast with a study by Kolawole and colleagues who reported IgM seroprevalence of $16 \%$ among pregnant women in Ilorin, Nigeria [16]. The difference in the observation may be attributed to the level of exposure to the vector of the virus at the two different locations and the fact that Ilorin is more of rural settings and less developed compared to Lagos and thus, gives room to untidy environments and bushes which harbours the vector. Moreover, in the rural settings such as Ilorin, the income earning power is lower compared to Lagos and as such, the use of treated mosquito nets and insecticides may not be affordable. These could also be the reasons why Mathe and co-workers reported a slightly higher seroprevalence among pregnant women in the North Central part of Nigeria which is more rural than Lagos. The observed low ZIKV seroprevalence rate though may not be significant, but suggests that Zika virus IgG titers may drop over time [17].

The specificity and sensitivity of the different ELISA kits used as well as the laboratory processes used across the various seroprevalence studies may also play a major role in the results differentials [3]. Other seroprevalence studies conducted across some African countries such as; Zambia $(6.1 \%)$, Cameroon $(5 \%)$, Rwanda $(1.4 \%)$ and Kenya (0.24$7.11 \%$ ) [3] recorded the corresponding seroprevalence rates. However, these rates cannot be directly compared to the 
result from these studies as the populations studied are significantly different.

The result from the real time PCR which shows that there was no detectable viral RNA in the plasma of the IgM seropositive individuals signifies that the individual had no active infection as at when the samples were collected. This could be as a result of elapsing of the viremia window phase [18] or the viral load was far below the detection limit of the assay.

One of the major limitations to this study is its restriction to pregnant women. However, the choice of pregnant women as the subject of study was predicated on the fact that the effect of Zika virus is mostly pronounced among fetuses. Secondly, lack of neutralizing antibodies test to determine the actual immune status of the participants which actually is not the focus of the study. However, the aim of the study was achieved by serologically providing evidence of Zika virus in Lagos State.

In conclusion, this study shows that there is $1.4 \%$ and $2.0 \%$ IgM and IgG seropositivity among the population studied. This suggests that there is Zika virus infection in Nigeria. From the parameters evaluated, it can be seen that none of those seropositive imported the virus as they have not had any history of travel prior to this study; this suggests that the infection is a local exposure. The study also pointed out that the low level seropositivity signifies that there is no herd immunity among the population studied. Exposure to mosquito bites could be implicated in the viral transmission. I recommend investigation of ZIKV in mosquitoes in future studies.

\section{ACKNOWLEDGMENT}

I want to acknowledge Temilolu Eunice Joseph-Shaibu for her contribution in the data analysis and also Dr Naizhe Li for his assistance on molecular detection.

\section{COMPETING INTEREST}

There are no competing interests from the authors.

\section{FUNDING}

No funding was received for this study.

\section{REFERENCES}

[1] S.L. Hills, M. Fischer and L.R. Petersen, "Epidemiology of Zika virus infection," The Journal of Infectious Diseases 216(suppl_10): S868-74, 2017.

[2] D. Baud, D. J. Gubler, B. Schaub, M. C. Lanteri and D. Musso, “An update on Zika virus infection," The Lancet 390(10107): 2099-109, 2017.

[3] Y. W. Chien, T. C. Ho, P. W. Huang, N. Y. Ko, W. C. Ko and G. C. Perng, "Low seroprevalence of Zika virus infection among adults in Southern Taiwan," BMC Infectious Diseases 19(1):1-7, 2019.

[4] P. Boeuf, H. E. Drummer, J. S. Richards, M. J. Scoullar and J. G. Beeson, "The global threat of Zika virus to pregnancy: epidemiology, clinical perspectives, mechanisms, and impact," BMC Medicine 14(1):1-9, 2016.

[5] L. S. Muñoz, P. Barreras and C. A. Pardo, "Zika virus-associated neurological disease in the adult: Guillain-Barré syndrome, encephalitis, and myelitis," Seminars in Reproductive Medicine 34(5), 273-279, 2016.
[6] T. V. de Araújo, R. A. de Alencar Ximenes, D. de Barros MirandaFilho, W. V. Souza, U. R. Montarroyos, A. P. de Melo, S. Valongueiro, C. Braga, S. P.Brandão Filho, M. T. Cordeiro, E. Vazquez, "Association between microcephaly, Zika virus infection, and other risk factors in Brazil: final report of a case-control study," The Lancet Infectious Diseases 18(3):328-36, 2018.

[7] V. Duong, P. Dussart and P. Buchy, "Zika virus in Asia," International Journal of Infectious Diseases 54:121-8, 2017.

[8] D. Musso, T. Nhan, E. Robin, C. Roche, D. Bierlaire, K. Zisou, A. S. Yan, V. M. Cao-Lormeau and J. Broult, "Potential for Zika virus transmission through blood transfusion demonstrated during an outbreak in French Polynesia," Eurosurveillance 19(14): 20761, 2014.

[9] M. R. Duffy, T. H. Chen, W. T. Hancock, A. M. Powers, J. L. Kool, R. S. Lanciotti, M. Pretrick, M. Marfel, S. Holzbauer, C. Dubray and L. Guillaumot, "Zika virus outbreak on Yap Island, federated states of Micronesia," New England Journal of Medicine 360(24): 2536-43, 2009.

[10] A. D. Haddow, A. J. Schuh, C. Y. Yasuda, M. R. Kasper, V. Heang, R. Huy, H. Guzman, R. B. Tesh and S. C. Weaver, "Genetic characterization of Zika virus strains: geographic expansion of the Asian lineage," PLoS Neglected Tropical Diseases 6(2): e1477, 2012.

[11] O. Faye, C. C. Freire, A. Iamarino, O. Faye, J. V. de Oliveira, M. Diallo, P. M. Zanotto and A. A. Sall, "Molecular evolution of Zika virus during its emergence in the 20th century," PLoS Neglected Tropical Diseases 8(1): e2636, 2014.

[12] N. Berthet, E. Nakouné, B. Kamgang, B. Selekon, S. DescorpsDeclère, A. Gessain, J. C. Manuguerra and M. Kazanji, "Molecular characterization of three Zika flaviviruses obtained from sylvatic mosquitoes in the Central African Republic," Vector-Borne and Zoonotic Diseases 14(12):862-5, 2014.

[13] J. Charan and T. Biswas, "How to calculate sample size for different study designs in medical research," Indian Journal of Psychological Medicine 35(2):121, 2013.

[14] R. S. Lanciotti, O. L. Kosoy, J. J. Laven, J. O. Velez, A. J. Lambert, A. J. Johnson, S. M. Stanfield and M. R. Duffy, "Genetic and serologic properties of Zika virus associated with an epidemic, Yap State, Micronesia," Emerging Infectious Diseases 14(8): 1232, 2008.

[15] P. Mathé, D. Z. Egah, J. A. Müller, N. Y. Shehu, E. T. Obishakin, D. D. Shwe, V. C. Pam, M. O. Okolo, C. Yilgwan, S. S. Gomerep and J. Fuchs, "Low Zika virus seroprevalence among pregnant women in North Central Nigeria," Journal of Clinical Virology 105:35-40, 2018.

[16] O. M Kolawole, M,M Suleiman, E.P Bamidele. Molecular epidemiology of Zika virus and Rubella virus in pregnant women attending Sobi Specialist Hospital Ilorin, Nigeria.

[17] M. Aubry, A. Teissier, M. Huart, S. Merceron, J. Vanhomwegen, C. Roche, A. L. Vial, S. Teururai, S. Sicard, S. Paulous and P. Desprès, "Zika virus seroprevalence, French polynesia," Emerging Infectious Diseases 23(4):669, 2017.

[18] J. J. Waggoner, L. Gresh, M. J. Vargas, G. Ballesteros, Y. Tellez, K. J. Soda, M. K. Sahoo, A. Nuñez, A. Balmaseda, E. Harris and B. A. Pinsky, "Viremia and clinical presentation in Nicaraguan patients infected with Zika virus, chikungunya virus, and dengue virus," Clinical Infectious Diseases ciw589, 2016. 